\title{
The Effectiveness of Female Roles in the Disney Films
}

\author{
Yiwen Chen ${ }^{1, *}, \dagger$, Xuanya Huang ${ }^{2, \dagger}$ and Yifan Zou ${ }^{3, \dagger}$ \\ ${ }^{1}$ Beijing World Youth Academy, Beijing, 100016, China \\ ${ }^{2}$ Guangdong Country Garden School, Guangzhou, 51000. China \\ ${ }^{3}$ Suzhou foreign language school, Suzhou, 215000, China \\ *Corresponding author: guanghua.ren@gecacdemy.cn \\ These authors contributed equally
}

\begin{abstract}
Feminism is a movement that arose from the changes in women's consciousness of their rights and status in society. During the 20th century, a surge of the feminist movements promoted by education became a significant and decisive factor in the tremendous improvement of women's status all around the world. This paper aims to explore the social impacts of Disney films made in the United States in the 20th century. The paper further confirms the social identity theory and cognitive theory to point out how Disney movies promote the unity of feminists and how they raise the consciousness of rights and fight for women's rights. This paper concludes that Disney movies improve the inspiration for feminism and the independence of women, and just push the women's status in a positive direction. The process and development of feminist characters of Disney movies are then discussed and presented.
\end{abstract}

Keywords: Feminism, the United States, Disney's films, Feminist Character, Social Identity Theory, Cognitive theory.

\section{INTRODUCTION}

\subsection{Background}

Inequality between men and women has been an unresolved social problem for all times. Society comprises of men and women, but in a patriarchal society, sex in the family, education, and employment discriminates against women. However, with the awakening of the awareness of equality and rights and feminism, in the 20th century, there was a remarkable change in women's status in American society because of World War II.

From the 18th century to the 1920 s, when feminism emerged from the United States, feminism fought for equal educational rights, political rights, business circle, and property inheritance rights with men. From the First World War to the 1960s, it was the second stage of the feminist movement and also the period of stagnation in the development of feminism. After that, the third phase of the women's movement, the new feminist movement that started in the 1960s - fighting for the right of vote and labor, and establishing a national women's organization. These actions marked the change of social status of women, traditional sexist consciousness and concept and the direct impact of the social movements of the 1960s, the civil rights movement and peace movement. Hence, the movie, information expression of the 20th century in the USA, changed its perspective of male to female (see Figure1). However, the directors' ideas at that time were still very childish because of the Hollywood mainstream consciousness 


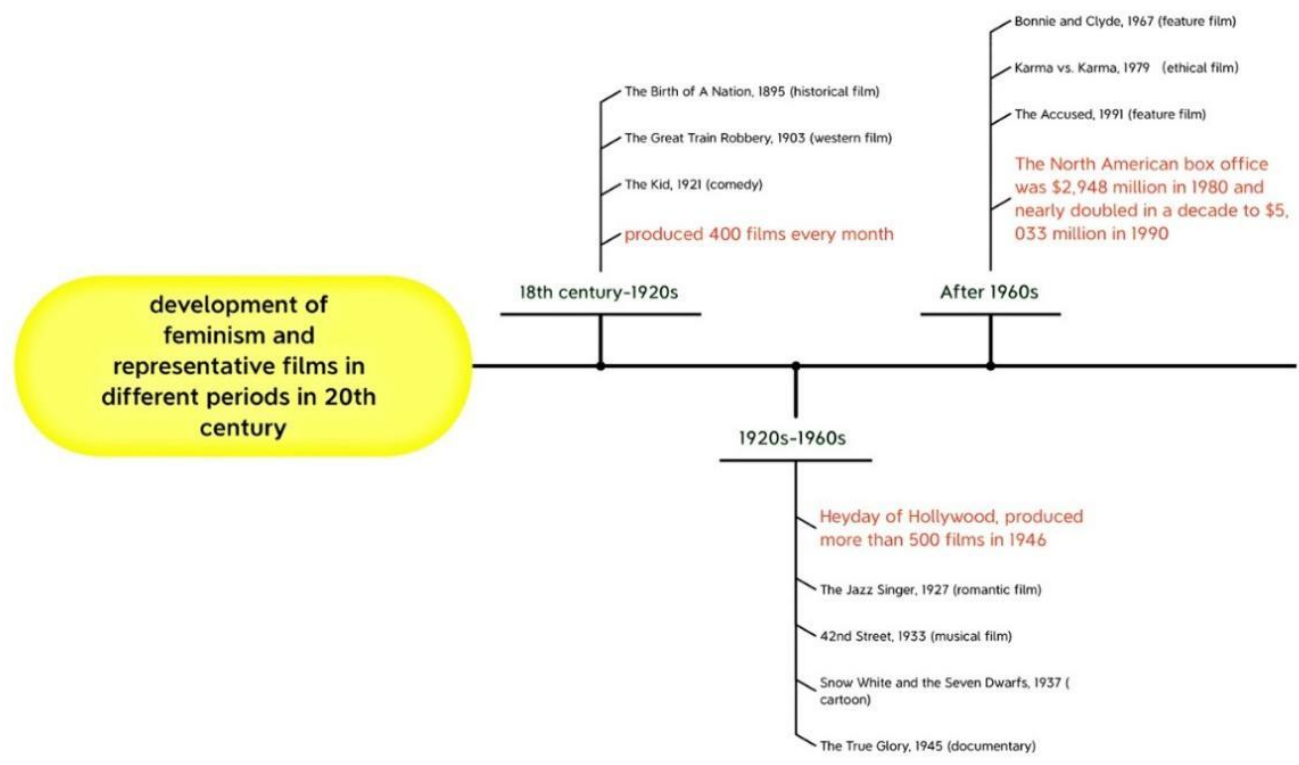

Figure 1 Timeline of development of feminism and representative films in different periods of 20th century [1]

\subsection{Character Features in Movies}

The earlier researches point out that the specific female traits, the heroic image of women, and the women's league are the mainstream features of twentieth-century movies [2]. For instance, building strong, independent, and successful women's image broke the male-dominated narrative of traditional Hollywood movies. Besides, women helped each other and reached the same goal-achieving equality and pursuing rights. Plus, they also divided into three characteristics - the feminine atheistic, female subjective, and female spectator.

For the feminine atheistic, the content of movies in the 1960s related to the relationship between women and others, such as the struggle and rebellion for the patriarchal society and sexual oppression, which marked the awakening of consciousness. Plus, there have been the activities, like robbing and architectural explosion, acted by women, which show the rebellions against the male-dominated society. Also, the second aspect of feminine atheism is women's roles. In the 20th century later, women's roles do not limit to mothers and wives who are still under the control of patriarchy but extend to occupations like business managers and CEO — changing the fixed image of women through the outlook and actions. Then, for female subjective, feminism films showed a female image which mentioned above - strong, independent, successful and heroic image. In addition, movies from the 1960 s onwards were more satisfying to female audiences because these told them that women could be liberated to do everything they has not been allowed to do in the past [3].

\subsection{Types of Movies in the 20th Century}

In the 20th century, war film and ethical film were popular types. The 1960s and later, Robert Benton's Krama vs. Krama in 1979 and Jonathan Kaplan's The Accused in 1988 are two representative movies that marked the image change of the female characters through three aspects mentioned above $[4,5]$. In contrast, there has been less early evidence for the effects of Disney film characters, so the paper aims to review female characters of Disney films that did not review before. Also, other's researches do not come down to the influence of the movies on their audience. North American animated films have a place in the development of the film industry (see Figure 2). Additionally, the building of female characters in the Disney movies was changed female image differently and the new female images in the Disney movies do influence both children and adults' minds. The characters because of the animation characters would likely influence the audience. In addition, every film will have a major idea or theory that the director wanted to tell to the people, like one of the social problems that society ignores. Thus, when the audience watches the movie, they will realize and absorb the key point that hides inside the plot and be affected.

Are there any impacts caused by Disney's female characters in the 20th century on audience and society? The hypothesis assumes as the women's role in society has been changed a lot to a positive direction in developing the feminist movies. Improvement brings more freedom and equality to women. The review paper assumes two significant theories for the topic and then going to explain feminism in Disney films. The paper will point out the influences and give a result to verify the hypothesis. 


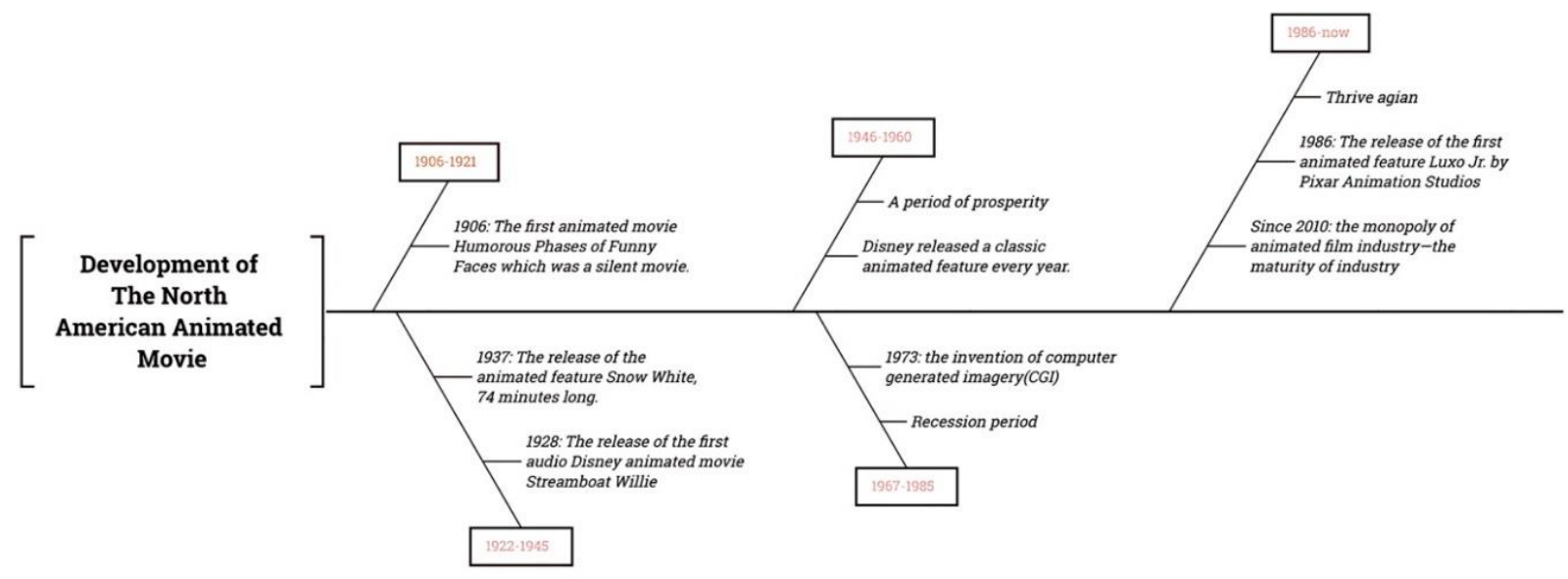

Figure 2 Timeline of the development of the North American animated movie [6].

\section{LITERATURE REVIEW}

\subsection{Social Identity Theory}

\subsubsection{Definition}

The term "social identity theory (SIT)" may confuse many people. However, social identity theory is a somewhat social psychology, which studies the interaction between individuals and social identity. Social identity theory aims to specify and predict situations in which individuals view themselves as individuals or group members [7]. The theory also considers the influence of personal and social identity on individual cognition and group behavior. People treat their group with preferential treatment and tolerance, and observe other groups of colored eyewear, with stereotypes of other groups. In a group, the behavior and idea of one person often represent the entire group, so easy to cause group conflict.

\subsubsection{Development}

In the 20th century, people were divided into two groups, one for men and one for women. In the 20th century, women were inferior to men, and men always stereotyped women: women had to do laundry, cooking, take care of children, can't go to work, be obedient to husband, these are their definitions of what a perfect wife is. There are three cores of the cognitive process-social classification, social comparison, and social identification. Social categorization in the 20th century was the idea that most men identified themselves as powerful male groups, separating themselves from women and female groups. The meaning of social comparison is very close to the literal meaning, referring to the social status of women compared to men in the 20th century. Social identity is the idea that people often stereotype other people because they belong to one group and influence the way they see things around them, so in the 20th century, it was the idea that men always stereotype women because they think they belong to the male group. Therefore, it is difficult to express individual characteristics in society, but through social identity. In Disney movies, the major groups of characters are still divided into male and female groups. In the early Disney female characters, the social status of female characters was very low, and they could not get rid of the male group's stereotype of the female group. Therefore, the detailed depiction of behaviors, languages, and thoughts of different gender groups in films can show the inferior status of women in the early 20th century, without free and independent life, and without their thoughts and awakening consciousness, but with developing society and passaging of time, more and more people realize they belong to the female group, so the female group is growing, they break many stereotypes, and awaken the ideas. Therefore, the image of Disney's female characters of the mid-20th century was the same. In the late 20th century, the power of the female group became stronger. Although the stereotype of other groups of the female group disappeared, there were still some defects. The roles of women in Disney movies changed [9].

\subsubsection{Conclusion}

SIT offers important insights about the social identity bases of discrimination, prejudice, and Inter-group conflict, by locating these phenomena as resulting from group-based categorization and self-enhancement motives [8]. Generally, people will feel positive about themselves and keep their self-esteem. It closely tied to somewhat emotional investment to the social standing of their in-groups. But if the comparison between one with the out-group's trend in the negative direction, the individuals will try to use strategies to improve the socials standing by giving themselves the message of motivation by the effect of the social identity theory. The first one is individual mobility. To reach a higher social level, individuals will choose to leave the current group and join 
a more satisfied group of higher and stronger social standing. The individual changes the status by moving the environment. The second one is social creativity, to adjust the dimension between in-groups without-groups to make the social standing change from negative to positive. Thus, leading to the relative social standing improvement. Social competition, which is the alter of the whole ingroups by the conflict with other out-groups to raise the social status of the group [10].

\subsection{Cognitive Theory}

\subsubsection{Definition}

Intuition largely dominates people's cognitive theory. Intuition usually controls people's language and thoughts through thoughts. In psychology, this is often referred to as mental suggestion, and the stage of mental suggestion is not simply through human thought, language, and behavior. Psychological cues also have a powerful influence on people, often through the environment and physiology. More specifically, through different ages, people have different thoughts and feelings about how they perceive and understand their surroundings. Because circumstances have changed so dramatically that they suddenly see something different at a similar age. Everyone has a different perspective on the same thing. These different perspectives of observation lead to and influence people to have different views and evaluations. The change of social environment will have a subtle influence on a person, because people are always easily influenced by things and opinions around them, especially the young children, which is why parents always emphasize the importance of a good learning environment.

\subsubsection{Development}

Mind and thinking processes have existed, and René Descartes observed that people have had instinctive ideas of birth, in 1647 [11]. The mid-18th century, which marked the starting stage of the scientific discipline of psychology [12]. The author concluded that Carl Wernicke discovered that there's a part in the brain that mainly deals with language comprehension and Paul Broca discovered that people's brain includes a part to charge language production, promoting the development of cognitive theory suddenly [12]. Then the development of computer science, World War II, and the cognitive revolution inspired the psychologist and shaped the cognitive theory to compound to a significant formal psychological discipline. Later, to find out the best mechanisms to train people to exert their largest potential and ability, the cognitive theory was utilized and blended into the study of behavior to break the challenge [12].

\subsubsection{Conclusion}

For cognitive theory, it is influenced by environmental events, physiological conditions, and cognitive processes - the three main factors affecting social cognition. Social cognitive theory indicates that people learn by observing others, with primary factors like environment, behavior, and person, which are in a reciprocal triadic relationship. Social cognition refers to individuals' thoughts and interpretations [13]. Plus, the four components of the Social Cognitive Theory can have some effects on motivation and goal attainment - selfobservation, self-evaluation, self-reaction, and selfefficacy. These four are interrelated and all have positive impacts on achieving individuals' goals. Self-observation and self-evaluation are both provisions of information to themselves, while the other two are encouragements of individuals' self-discovery [14]. However, there are still some limitations to it. This theory assumes the environment will change as people change, but it will not always be correct. Besides, it is loosely organized. Because it only considers the interaction between environment, behavior, and person. However, it is unclear the extent of the impacts on these factors of the actual activities. Also, it highly focuses on the learning process and ignores the effects of actual biological factors of behaviors and actions [15].

\subsection{Research Object}

\subsubsection{Definition}

Feminism is the belief in the social, economic, and political equality of the sexes. Although mainly originating in the West, feminism is manifested worldwide and is represented by various institutions dedicated to representing women. Women's rights. The feminist movement first carried out activities in distant antiquity, because it is obvious that feminism has a very long history. It has been going on throughout the ages, so its influence cannot be ignored [16].

\subsubsection{Development}

This paper focuses on eight Disney princess fairy tales to represent key eras and changes into Disney animation. They are Snow White and the Seven Dwarfs, Cinderella, Sleeping Beauty, The Little Mermaid, Mulan, Tangled, Brave and Frozen (see Figure 3-7) (in chronological order), the most recent films from the 20th to the 21 st century. These eight films were chosen for deeper scrutiny and research because they were released at different times and represented different ideals. Why media influence is important, how society influences and influences gender roles, these aspects still need to be discovered, and what stereotypes or expectations about female roles have existed throughout American history. This paper is divided the eight films into three stages. 


\subsubsection{Influences}

The major representative works of the first stage are Snow White and Cinderella (see Figure 4 and Figure 5) $[17,18]$. They were created in the 1950s in the United States in a happier era after World War II, when many families moved to the suburbs and lived a happy life with the American dream [19]. During this period, as men returned to the war and women returned to the kitchen, a sense of gender reconfiguration reemerged. Men are expected to be the breadwinners, while women are the caretakers of the home, caring only about the children and the family. Because society's ideal image of women is always portrayed as baking bread or cleaning, to imitate the role women should play in society.

The second major work was The Little Mermaid (see figure 6), which was released in 1989 and created a new role model for women and young girls as the feminist movement grew in the 20th century [20]. Ariel, the protagonist, is different from the princesses before her, not only because of her clothes but also because of her personality, ambition, and courage. She is also unyielding to authority and eager to be herself and make her way. Ariel was the first Disney princess before her to sing and talk about her wishes. Although she was the first princess to become a rebel and fight for what she wanted, her story. However, she still needs to marry a prince and live as a male. Ariel's character was a big change in Disney and their previous representation of women. Her character is the beginning of a new era of Disney and a role model for Disney princesses.

In the third stage, the most representative work is Brave [21]. It was the first time Disney had created a princess that was a turning point in history. The protagonist, Melida, represents Disney's progress, and the stereotypical labels it once created, but still changing. Their creation of Melida set the standard for the princesses who came after her to become independent, free, and truly heroic, free from the constraints on family and female dependence. At the same time, Brave also represents the current social situation, female status, and female thought.

Disney has a huge influence not only in the entertainment industry but also in society. Disney has been around for more than 80 years, and during that time, they have played a role in how society presents gender roles. As modern culture has changed, Disney has also changed the way they present their characters, especially women. Disney creates female characters in movies based on social problems and needs. Almost all female characters are the same as the female images of the society at that time (20th century), no matter their working style or life attitude or the end of life. Disney is a movie not only for adults but also for children, so the influence is powerful and widespread. Disney studies the concept of gender roles and how society reflects on what is socially acceptable and normal among men and women. Many children get information about gender roles and other beliefs or values from media sources. The depiction of female characters can be described in at least one of three ways. First, the original image of Disney princesses is a typical damsel in distress, very family. A second description emerges and transforms the female character into rebellious and ambitious. Third, a final shift takes place, where female characters are portrayed as independent and free spirits. These different types of female images can be seen through different films, which coincide with the cultural aspects of the same period. Surrounding cultures, beliefs, ideals, and expectations are selected for review and study through various Disney films. Therefore, Disney films are very important to enlightening, awakening, and determination of women's independent thought. Disney continued to grow and make more and more movies. They are still trying to cultivate and develop the idea of a princess, more multicultural, multi-ethnic. Disney will continue to enlighten their audiences about gender roles.

In the society of the 20th century, the female characters in Disney films had a great influence on women in the society at that time. Women in the 20th century gradually changed, not only in their minds but also in their actions. As the female characters in Disney films became independent, confident and brave, women in 20th-century society became divorced from their families and refused to rely on men and families (many women began to look for jobs and can live alone instead of housewives). They no longer sacrifice themselves for family and marriage. For example, many of them choose to bravely break away from marriage and keep learning to enrich themselves, because if they want to be valued and equal, they must first improve their abilities and create opportunities for themselves. These women are called new thought women and new age women, and most of them aim to pursue equal social status. 


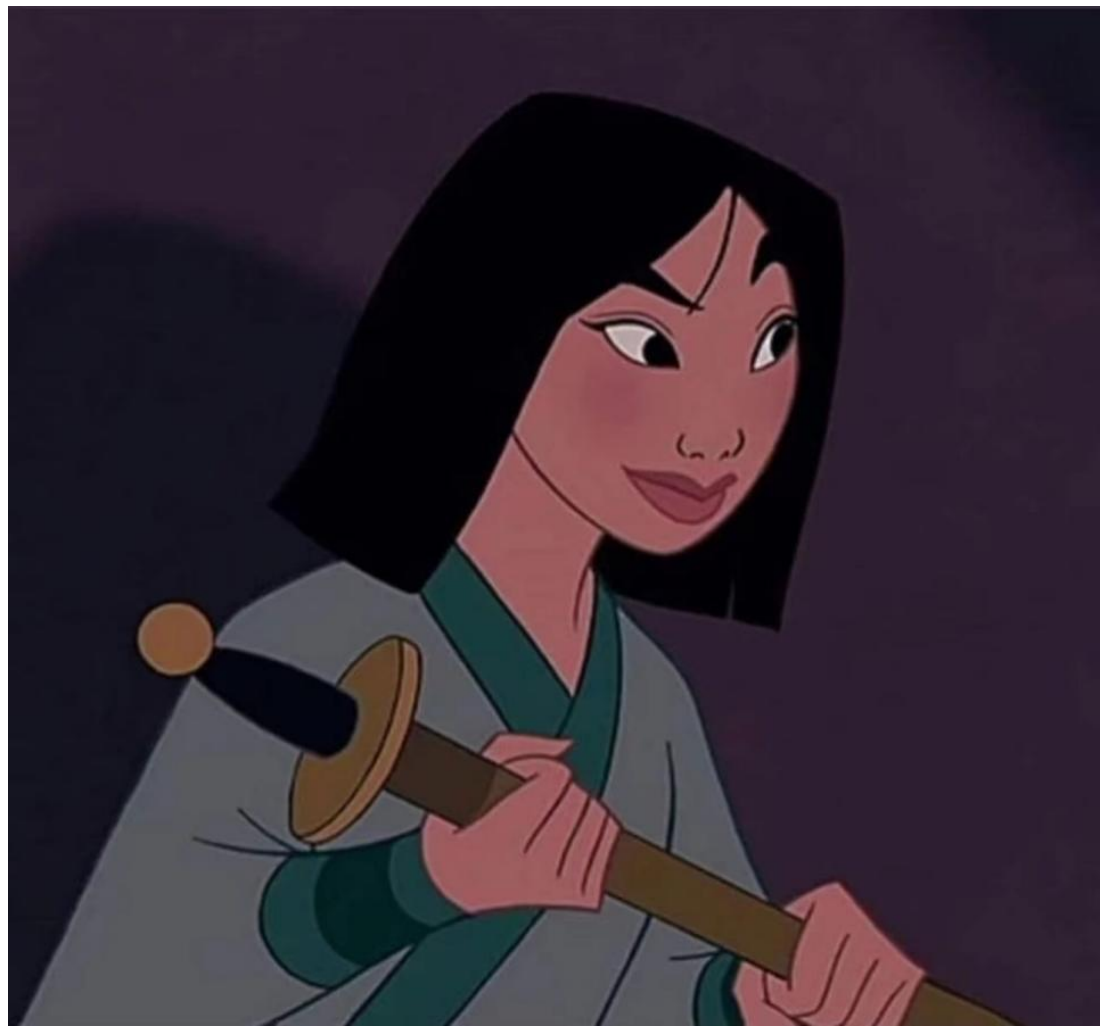

Figure 3 Mulan

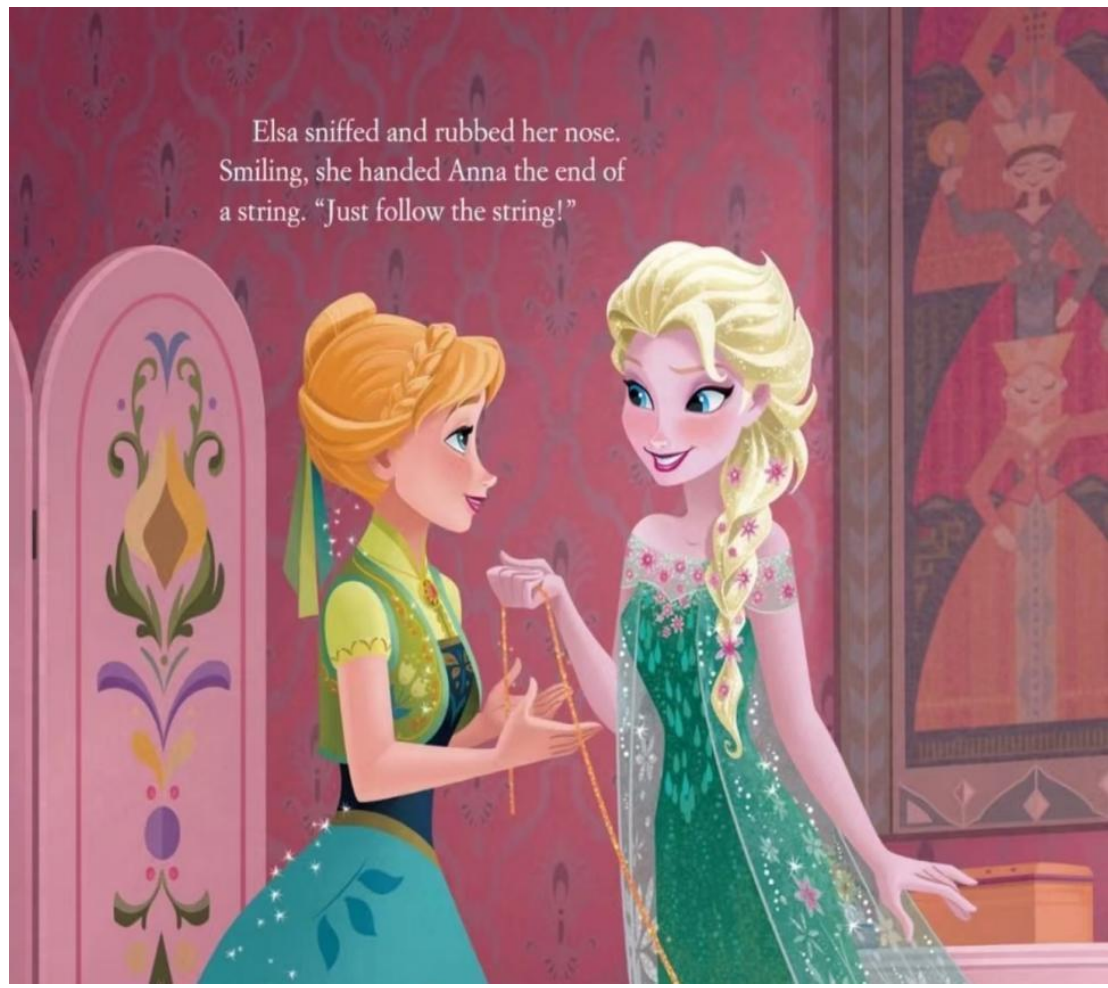

Figure 4 Elsa 


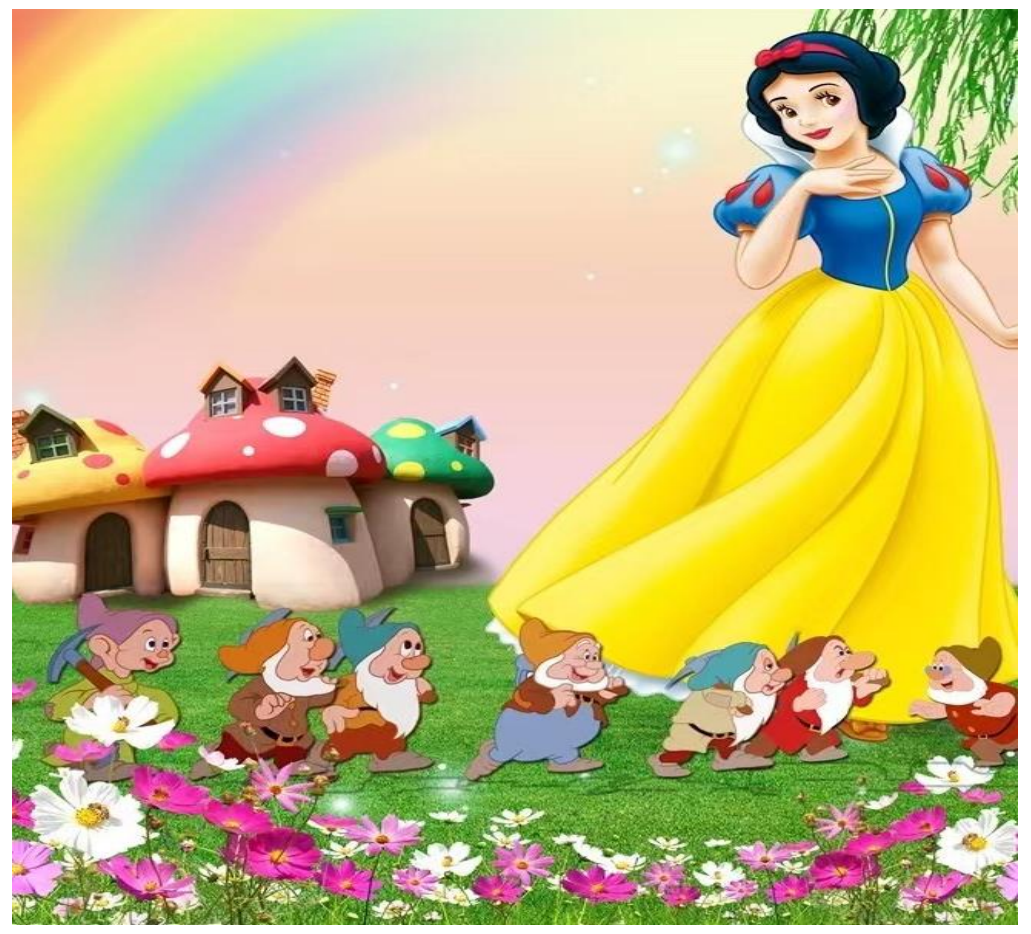

Figure 5 Snow White [17]

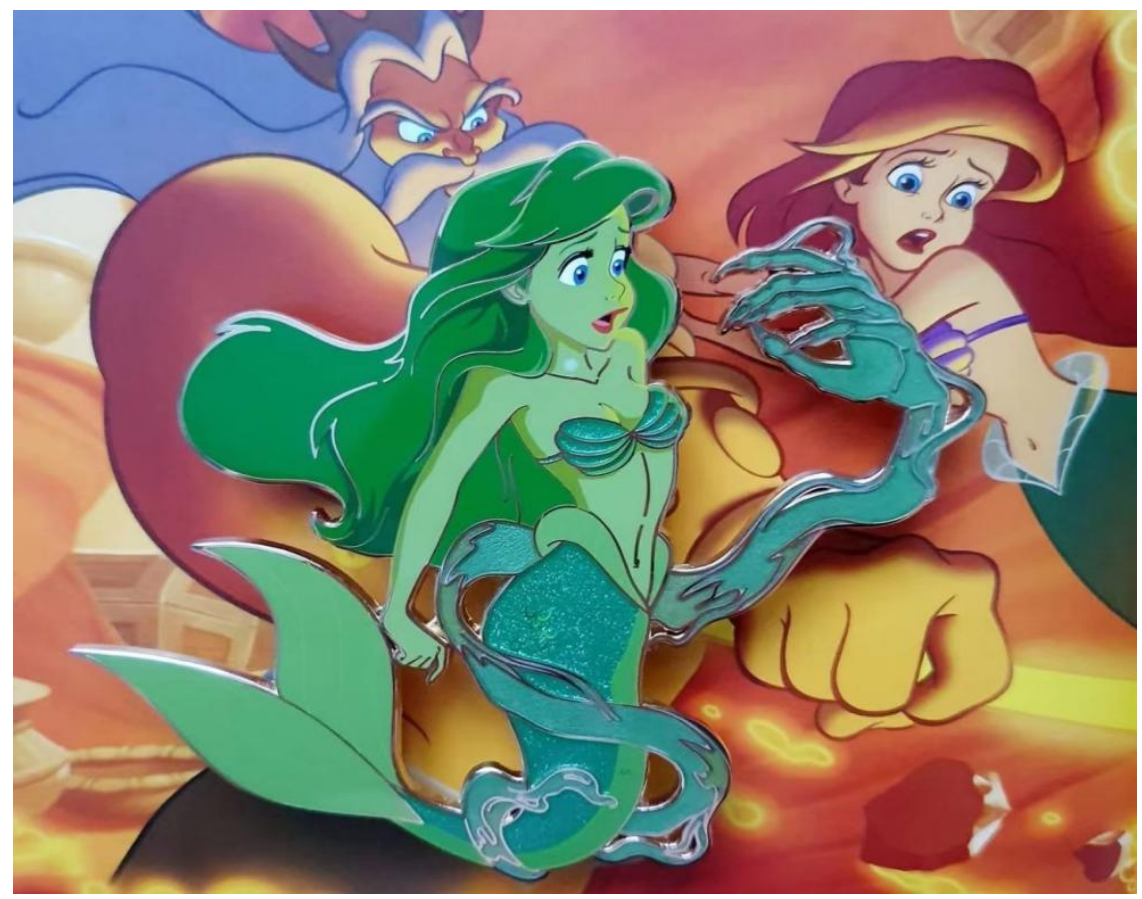

Figure 6 Cinderella [18] 


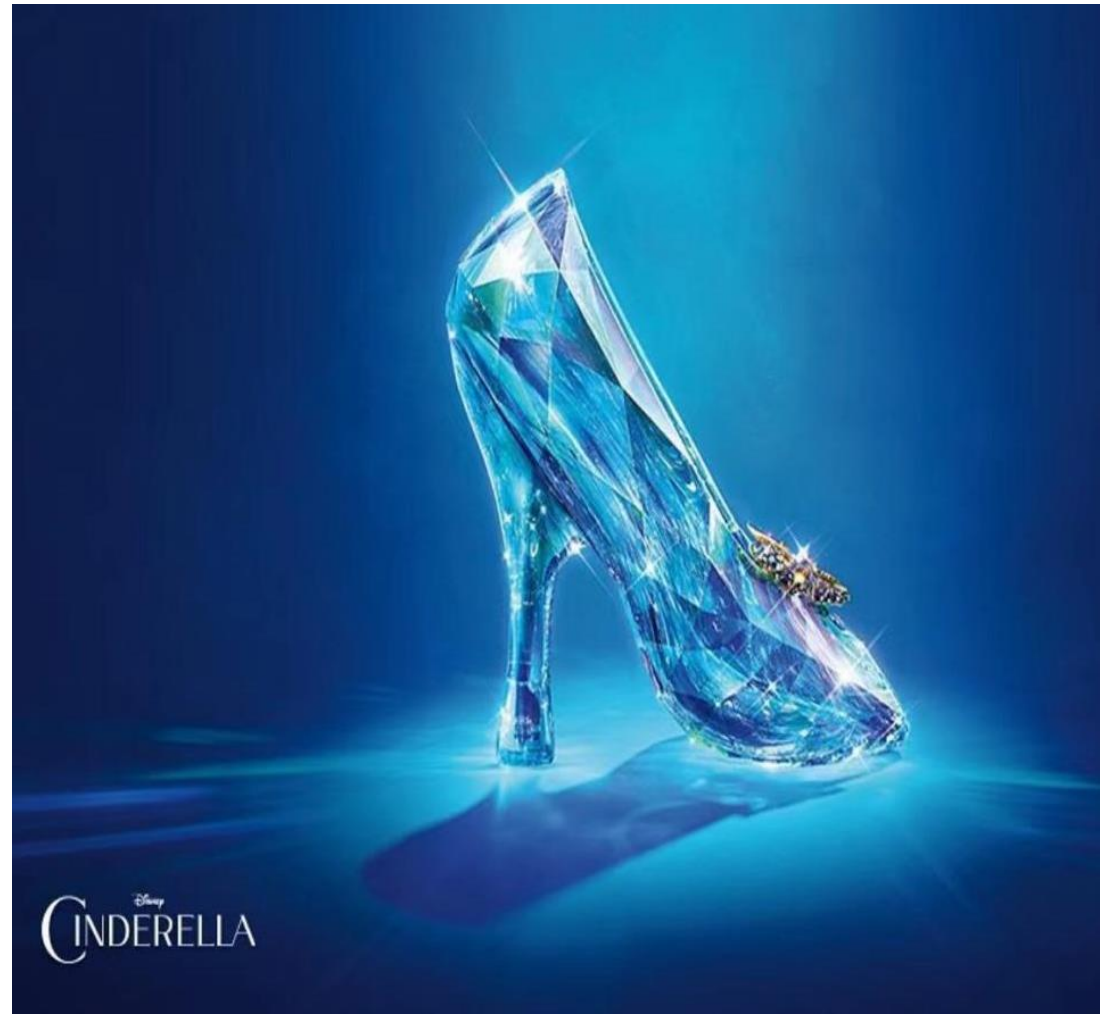

Figure 7 Ariel

\section{RESULTS AND DISCUSSION}

In the early 20th century, the researchers created the first Disney film with female characters, in which Snow White's influence perfectly matched the image of women in society at that time. But as the 20th century ushered in many changes, so did Disney's female characters.

These changes reflect the rising desire of women in the 20th century to be free, not to be tied down, to be independent. At the same time, women in society were also inspired by Disney movies and began to make a series of changes and rebellions. In the initial hypothesis, it is mentioned that with the development of feminist films, the role of women in society has changed greatly and is developing in a positive direction. After researching, this paper pointed out that the results of the facts are in perfect agreement with the content of the hypothesis. From the trend of Disney's influence and reflected the content, Disney's female characters are pushing women's status can be found in a positive direction step by step. From Snow White as a female character of Brave today. Disney's films cater to and refer to the status quo and status of women in society to create stories, so it is not difficult to see from Disney's films that women are gradually independent, free and get rid of their dependence on family and men.

The Result and the Result from Literature Review are the same because they both conclude that the status of women will be higher and higher with the development of the times and will be more and more recognized. In terms of predicting future development, the result demonstrates that the diversity and awakening consciousness of female characters of films will still influence and enlighten women, enabling women to develop to a new height of social status. Also, in future movies, female characters will become more independent, free, and have new ideas. However, it is impossible to avoid the female role or to cater to the market demand, to create the most common female images in the current society and the difficulties faced by women.

\section{CONCLUSION}

According to the research question, the paper studies the female characters in Disney movies based on the research background of the 20th century. The main research is the influence of female characters in Disney films on women in the 20th century. When studying the female characters in Disney movies, this paper mainly uses references and real movies. For the 20th century, the female characters in Disney films have been changing. They have become more independent, self-contained and innovative. Therefore, it concludes that the female characters in Disney films have an authentic and vital impact on the changes of women in the 20th century. Women in society in the 20th century changed with the new image of female characters in Disney films. Therefore, it can be concluded that there are certain female characters in Disney films in the 20th century that have influence. At the same time, this is the same hypothesis proposed above. The hypothesis above before 
the study was that female characters in Disney films influenced the change of women in the 20th century. The hypothesis is based on the changing status of women in today's society and the image of female characters in today's Disney movies. Through the research, this study argues that the images of female characters in Disney films will be more innovative and independent, and become women of the new era because you can see it in the comparison between the original Snow White and the latest Elsa. Disney movies are very popular and popular all over the world (applicable to all ages), so they have a great influence on people's subconscious behaviors and thoughts, so women's social status will become higher and more influential.

\section{REFERENCES}

[1]. Lule, Jack. "8.2 The History of Movies." Understanding Media and Culture, University of Minnesota Libraries Publishing Edition, 2016. This Edition Adapted from a Work Originally Produced in 2010 by a Publisher Who Has Requested That It Not Receive Attribution., 22 Mar. 2016, https://open.lib.umn.edu/mediaandculture/chapter/8 -2-the-history-of-movies/.

[2] Lijun Bian. "The character of american feminist film." Film Literature, 2016, pp. 43-45, qikan.cqvip.com/Qikan/Article/Detail?id=6694004 86.

[3] Shen Min. "Feminist Studies in American Films from the 1960s to the Present." Shanghai overseas Chinese University.CNKI, May 2010, cdmd.cnki.com.cn/article/cdmd-102711011017965.htm.

[4] Benton, Robert. Kramer vs. Kramer, Colombia Pictures, 1979 , https://en.wikipedia.org/wiki/Kramer_vs._Kramer. Accessed 2021.

[5] Kaplan, Jonathan, director. The Accused. The Accused, The 39th Berlin International Film Festival, 1988 https://en.wikipedia.org/wiki/The_Accused_(1988 film). Accessed 2021.

[6] Motalová, Zuzana. "The History of American Animation.” ReViews Magazine, 20 Sept. 2021, http://reviewsmagazine.net/the-history-ofamerican-animation/.

[7] Ellemers, Naomi. "social identity theory". Encyclopedia Britannica, 16 Nov. 2020, https://www.britannica.com/topic/social-identitytheory. Accessed 30 October 2021.

[8] Islam, Gazi. "(PDF) Social Identity Theory." ResearchGate, 2014 , https://www.researchgate.net/publication/28120833 8_Social_Identity_Theory.

[9] Vinney, Cynthia. "Social Identity Theory and and Its Impact on Behavior." ThoughtCo, ThoughtCo, 22 July 2019, https://www.thoughtco.com/socialidentity-theory-4174315.

[10] social identity theory, https://www.britannica.com/topic/social-identitytheory, Encyclopædia Britannica, October 30, 2021

[11] Mansell, W. (2004). Cognitive Psychology and Anxiety. Psychiatry, 3(4), 6-10.

[12] "Cognitive Theory: History, Strength and Weaknesses: Free Paper Examples." Premium, https://premium-papers.com/cognitive-theoryhistory-strength-and-weaknesses/.

[13] "What Are the Main Factors That Can Affect Social Cognition within a Family?" Oman Essay, 2019, https://askinglot.com/open-detail/77591.

[14] "Social Cognitive Theory Components." Page Loading in a Moment, 2010, https://askinglot.com/goto/77591A5.

[15] LaMorte, Wayne. "Behavioral Change Models." The Social Cognitive 2019, https://sphweb.bumc.bu.edu/otlt/MPH-

Modules/SB/BehavioralChangeTheories/Behaviora 1ChangeTheories5.html.

[16] Burkett, Elinor and Brunell, Laura. "feminism". Encyclopedia Britannica, 27 Aug. 2021, https://www.britannica.com/topic/feminism. Accessed 11 November 2021.

[17] Disney, Walt, et al. Snow White and the Seven Dwarfs. Snow White and the Seven Dwarfs, 1937, https://en.wikipedia.org/wiki/Snow_White_and_the _Seven_Dwarfs_(1937_film). Accessed 2021.

[18] Peed, William, et al. Cinderella, Distributed by RKO Radio Pictures, Inc., 1950 , https://en.wikipedia.org/wiki/Cinderella_(1950_fil m). Accessed 2021.

[19] History.com Editors. "World War II." History.com, A\&amp;E Television Networks, 29 Oct. 2009, https://www.history.com/topics/world-war-ii/worldwar-ii-history.

[20] Ashman, Howard. The Little Mermaid. Walt Disney Feature Animation and Walt Disney Pictures, 1989, https://en.wikipedia.org/wiki/The_Little_Mermaid_ (1989_film). Accessed 2021.

[21] Andrews, Mark, et al., directors. Brave, 2012, https://en.wikipedia.org/wiki/Brave_(2012_film). Accessed 2021. 